\title{
Systolic and diastolic time intervals in young diabetics
}

\author{
ANDRZEJ RYNKIEWICZ, EWA SEMETKOWSKA-JURKIEWICZ, \\ BOGDAN WYRZYKOWSKI
}

\author{
From the II Clinic Institute of Internal Medicine, Medical Academy, Gdansk, Poland
}

SUMMARY Systolic and diastolic time intervals were used to examine left ventricular performance in 22 young diabetic men (mean age 25 years) with no apparent clinical heart disease. Pre-ejection period index (PEPI), left ventricular ejection time index (LVETI), electromechanical systole index $\left(\mathrm{QS}_{2} \mathrm{I}\right)$, PEP to LVET ratio, the a wave percentage amplitude of the apexcardiogram $(\mathrm{a} / \mathrm{H} \%$ ratio), the rapid filling wave (RFW), and the $\mathrm{A}_{2} \mathrm{O}$ interval were obtained in the conventional manner in 22 diabetics and 22 healthy men. The heart rate, diastolic pressure, PEP/LVET ratio, a/H per cent ratio, and $\mathrm{A}_{2} \mathrm{O}$ interval were significantly increased and LVET decreased in the diabetic group. QS $\mathrm{S}_{2} \mathrm{I}, \mathrm{PEPI}$, and RFW did not differ from that in the normal group. Twenty-three per cent of patients had an abnormal systolic time interval, 54 per cent an abnormal diastolic time interval, and 23 per cent had both abnormal intervals. Though these studies provide no definite evidence of a cause, the abnormalities found may reflect a subclinical diabetic cardiopathy.

Cardiac disease has been found to be one of the major complications of diabetes mellitus and for many years was attributed to coronary atherosclerosis. Recently the terms diabetic cardiopathy and diabetic cardiomyopathy have appeared in medical publications. ${ }^{1}$ These terms imply the existence of a specific diabetic heart disease, a new nosological entity that has been growing out of several studies performed during the last few years by research workers in diabetes. The assessment of left ventricular function as an index of potential myocardial involvement in diabetic patients without clinical evidence of myocardial ischaemia or other cardiovascular abnormalities has become increasingly important. ${ }^{2}$ This study was undertaken to investigate ventricular function as a measure of potential myocardial involvement in young patients with diabetes mellitus. Non-invasive measurement of the systolic and diastolic time intervals provide a reasonable correlation with more direct measures of cardiac performance in the absence of complicating lesions such as valvular or pulmonary disease. $^{3} 4$

\section{Subjects and methods}

The function of the left ventricular myocardium was evaluated in 22 diabetic men ranging in age Received for publication 8 January 1980 from 20 to 29 years with no apparent clinical heart disease. Subjects were selected who were ambulatory clinic patients or who had recovered at least one week previously from an episode of ketoacidosis that required admission to hospital. All patients had normal blood pressure, were in sinus rhythm, and had no $x$-ray film evidence of cardiac abnormality. However, five patients had signs of left atrial enlargement in their electrocardiograms. Three patients had non-proliferative retinopathy, but none had renal or neurological complications. Each subject was carefully interviewed to exclude from the study subjects with a history of chronic alcoholism. Details of the mean duration of their diabetic status, treatment, blood pressure, and heart rate are listed in Table 1 . On the basis of the duration of treatment the diabetic patients were divided into two groups (see Table 3). Group 1: the duration of treatment from three months to five years; group 2: the duration of treatment from five years to 16 years. Twenty-two healthy men (mean age 24 years) served as a control group.

Simultaneous electrocardiogram (lead II), phonocardiogram from the third left intercostal space parasternally, a carotid pulse tracing, or apexcardiogram were recorded during the resting period preceding the measurement of resting blood pressure. The carotid pulse tracing was recorded 
Table 1 Clinical data of diabetic and healthy men

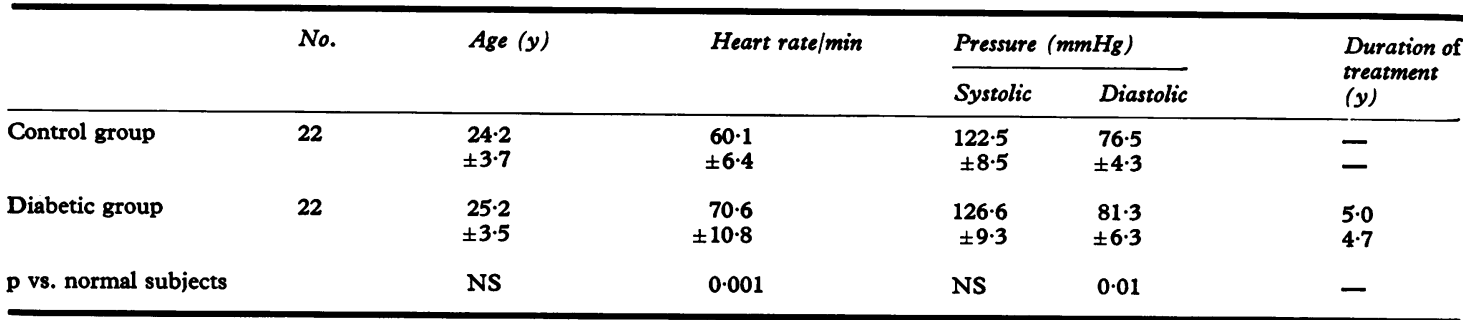

NS, not significant $(p<0.05)$. Listed are mean values $\pm S D$.

in the supine position and the apexcardiogram in the left lateral position, both during relaxed expiratory apnoea. All the curves were recorded on a direct writing 8-channel mingograph (EM 82. Siemens Elema AB, Sweden). A pulse/phono transducer 860 , with time constant $4.5 \mathrm{~s}$ was used. The paper speed was $50 \mathrm{~mm} / \mathrm{s}$ for the electrocardiogram and $100 \mathrm{~mm} / \mathrm{s}$ for the other tracing. The apexcardiogram contributed to three of the variables in this study (diastolic time intervals): the $\mathrm{a} / \mathrm{H}$ per cent ratio, that is the a wave percentage amplitude of the total deflection $(\mathrm{H})$ of the apexcardiogram, the $\mathrm{A}_{2} \mathrm{O}$ interval, that is the interval between the aortic component of the second sound and the O-point of the apex curve; the rapid filling wave (RFW) was measured from its beginning (Opoint) to the site where the contour deviated toward the horizontal line. Total electromechanical systole $\left(\mathrm{QS}_{2}\right)$ was measured from the onset of the QRS complex of the electrocardiogram to the highfrequency component of the second heart sound. Left ventricular ejection time (LVET) was measured from the beginning of the rapid upstroke of the carotid pulse to the nadir of the incisura. The pre-ejection phase was derived by subtracting the left ventricular ejection time from $\mathrm{QS}_{2}$. The measurements on 10 consecutive beats were determined to the nearest $5 \mathrm{~ms}$ and then averaged. Indices of systolic time intervals $\left(\mathrm{QS}_{2} \mathrm{I}, \mathrm{LVETI}\right.$, and PEPI) were derived from the actual measured intervals by applying the regression equation. ${ }^{5}$ Resting blood pressure was measured after the non-invasive examination after approximately half an hour's rest; casual blood pressure was measured in the seated position with a mercury manometer and a stethoscope.

Statistical analyses of the results were made by Student's $t$ test.

\section{Results}

Diabetic patients had slightly higher levels of heart rate $(p<0.001)$ and arterial diastolic pressure $(p<0.01)$ that were significantly different from normal subjects, but within the normal range (Table 1). The abnormalities of systolic time intervals in the diabetic subjects included a shorter LVETI and an increase in the ratio of PEP to LVET (Table 2) compared with that in the healthy men. Both $\mathrm{QS}_{2} \mathrm{I}$ and PEPI were of similar duration to that in the control group. The mean values for the $\mathrm{A}_{2} \mathrm{O}$ interval and the $\mathrm{a} / \mathrm{H}$ per cent ratio were significantly higher in diabetic patients. The rapid filling wave in diabetics did not differ from that in the normal subjects. We did not find any correlations between systolic time intervals or diastolic time intervals and diastolic pressure in the control and diabetic groups. The mean values $\pm 2 S D$ in

Table 2 Systolic and diastolic time intervals in diabetic and normal subjects ( $m s$ )

\begin{tabular}{|c|c|c|c|c|c|c|c|c|}
\hline & No. & LVETI & $P E P I$ & $Q S_{2} I$ & $P E P / L V E T$ & $\mathrm{~A}_{2} \mathrm{O}$ & $R F W$ & $\begin{array}{l}a / H \\
\text { per cent }\end{array}$ \\
\hline Normal group & 22 & $\begin{array}{l}397 \cdot 6 \\
\pm 12.3\end{array}$ & $\begin{array}{r}117 \cdot 7 \\
\pm 12 \cdot 5\end{array}$ & $\begin{array}{l}516 \cdot 2 \\
\pm 10 \cdot 2\end{array}$ & $\begin{array}{r}0.31 \\
\pm 0.05\end{array}$ & $\begin{array}{r}106.9 \\
\pm 7.5\end{array}$ & $\begin{array}{r}70.5 \\
\pm 13.8\end{array}$ & $\begin{array}{r}8.5 \\
\pm 3.8\end{array}$ \\
\hline Diabetic group & 22 & $\begin{array}{l}388 \cdot 5 \\
\pm 14 \cdot 3\end{array}$ & $\begin{array}{r}124.9 \\
\pm 13.8\end{array}$ & $\begin{array}{r}510 \cdot 7 \\
\pm 15 \cdot 8\end{array}$ & $\begin{array}{r}0.35 \\
\pm 0.05\end{array}$ & $\begin{array}{r}121 \cdot 1 \\
\pm 18.9\end{array}$ & $\begin{array}{r}71 \cdot 5 \\
\pm 8 \cdot 5\end{array}$ & $\begin{array}{r}11.5 \\
\pm 4.0\end{array}$ \\
\hline
\end{tabular}

Listed are mean values $\pm S D$

LVETI, left ventricular ejection time index; PEPI, pre-ejection period index; $\mathrm{QS}_{2} \mathrm{I}$, electromechanical systole index; $\mathrm{A}_{2} \mathrm{O}$ interval between aortic component of second sound and O-point of the apex cardiogram; RFW, rapid filling wave; a/H, ratio of a wave amplitude to maximum deflection of the apex cardiogram. 
Table 3 Systolic and diastolic time intervals in diabetics with different duration of treatment

\begin{tabular}{|c|c|c|c|c|c|c|c|}
\hline & $Q S_{2} I$ & LVETI & PEPI & $P E P / L V E T$ & $\mathrm{~A}_{2} \mathrm{O}$ & $R F W$ & $\begin{array}{l}a / H \\
\text { per cent }\end{array}$ \\
\hline $\begin{array}{r}\text { Group } 1 \\
\text { no. } 12\end{array}$ & $\begin{array}{r}512.0 \\
\pm 8.2\end{array}$ & $\begin{array}{l}389.8 \\
\pm 11.9\end{array}$ & $\begin{array}{r}128.8 \\
\pm 13.5\end{array}$ & $\begin{array}{r}0.33 \\
\pm 0.04\end{array}$ & $\begin{array}{r}115.4 \\
\pm 16.5\end{array}$ & $\begin{array}{r}70 \cdot 9 \\
\pm 7 \cdot 9\end{array}$ & $\begin{array}{r}12 \cdot 7 \\
\pm 4 \cdot 3\end{array}$ \\
\hline \multirow[t]{2}{*}{$\begin{array}{r}\text { Group } 2 \\
\text { no. } 10\end{array}$} & $\begin{array}{r}509.9 \\
\pm 18.4\end{array}$ & $\begin{array}{r}381 \cdot 4 \\
\pm 12 \cdot 3\end{array}$ & $\begin{array}{r}123 \cdot 2 \\
\pm 12 \cdot 2\end{array}$ & $\begin{array}{r}0.36 \\
\pm 0.05\end{array}$ & $\begin{array}{r}123.4 \\
\pm 19.9\end{array}$ & $\begin{array}{r}72 \cdot 2 \\
\pm 8 \cdot 2\end{array}$ & $\begin{array}{r}9 \cdot 7 \\
\pm 2 \cdot 9\end{array}$ \\
\hline & NS & NS & NS & NS & NS & NS & NS \\
\hline
\end{tabular}

Listed are mean values \pm SD.

For abbreviations see Table 2 .

the healthy young men were taken as the normal range for each of the indices. Five diabetics (23\%) had at least one abnormal systolic time interval, and $12(54 \%)$ patients had at least one abnormal diastolic time interval. Five patients $(23 \%)$ had both abnormal systolic and diastolic time intervals. There were no differences in the systolic or diastolic indices in the two diabetic groups between treatment of long or short-term duration (Table 3). Three patients with retinopathy had at least one abnormal systolic or diastolic time interval. Two patients with left atrial enlargement on the electrocardiogram had an abnormal $\mathrm{a} / \mathrm{H}$ per cent ratio. There was no association between the quality of previous diabetic control and the abnormalities in the systolic or diastolic time intervals.

\section{Discussion}

A group of young asymptomatic diabetic patients was selected to evaluate myocardial performance in diabetics without overt cardiac disease. Until recently there have been only a few exact studies of cardiac function in diabetes mellitus. Most of the results available were obtained with the systolic time intervals technique. ${ }^{6}{ }^{7}$ Our study shows a significant shortening of the left ventricular ejection time index $(p<0.05)$ and an increase in the ratio between PEP and LVET $(p<0.05)$ in the diabetic young men. Though a shorter left ventricular ejection time (LVET) and a higher PEP/LVET ratio is characteristic of the failing heart, ${ }^{58}$ the moderate abnormalities of these indices in our diabetic patients may not be exclusively related to an abnormality of myocardial contractility. That altered preload may at least contribute to, if not constitute the major determinants of, this preclinical abnormality is suggested by the significantly higher $\mathrm{a} / \mathrm{H}$ per cent ratio in the diabetic group. ${ }^{9}$ Good correlation has been shown between the relative magnitude of the a wave and an index of the left ventricular distensibility ${ }^{10}$ or the left ventricular end-diastolic pressure. ${ }^{9}$ The interval between the aortic component of the second heart sound and the $O$-point in the apexcardiogram $\left(\mathrm{A}_{2} \mathrm{O}\right)$ was longer in diabetic patients $(\mathrm{p}<0.01)$. Signs of reduced distensibility of the left ventricle were not in parallel with prolongation of the $\mathrm{A}_{2} \mathrm{O}$ interval (only one patient with abnormal $\mathrm{A}_{2} \mathrm{O}$ interval had abnormal $\mathrm{a} / \mathrm{H}$ per cent ratio) so that this cannot be the main cause of the prolonged $\mathrm{A}_{2} \mathrm{O}$ interval. The prolongation of the $\mathrm{A}_{2} \mathrm{O}$ interval could not be explained by differences in heart rate or diastolic pressure (both higher in the diabetic group) since there was no correlation between the $\mathrm{A}_{2} \mathrm{O}$ interval and heart rate or diastolic pressure in the control and diabetic groups. Manolas and Rutishauser ${ }^{4}$ showed that the $\mathrm{A}_{2} \mathrm{O}$ interval was closely correlated with internally measured indices of relaxation and less closely but still significantly with isovolumic contractile indices and ejection fraction in patients with nonobstructive cardiomyopathy. Wikstrand ${ }^{11}$ suggested that impaired interrelation between the intensity of the contractile state and the velocity of relaxation may prolong relaxation of the heart and the $\mathrm{A}_{2} \mathrm{O}$ interval. Further studies are required to elucidate the reasons for this prolongation of the $\mathrm{A}_{2} \mathrm{O}$ interval in diabetic patients. We have found an abnormal systolic time interval in 10 young diabetics and an abnormal diastolic time interval in 17 diabetic patients. Thus, when impairment of left ventricular function is studied at an early stage, interest should be concentrated not only on systole, but also on diastole. Recently Sanderson et al.,12 using echocardiography, reported abnormalities of diastolic function in 17 of $23^{\circ}$ young diabetics, most of them with retinopathy. Five of our diabetics had signs of left atrial enlargement in their electrocardiograms, two of whom had an abnormal a/H per cent ratio. However, Zoneraich et al. ${ }^{13}$ suggested that the $\mathrm{P}$ wave abnormalities in diabetics were the result of intraatrial conduction disturbances or of intra-atrial block and rarely of left atrial enlargement.

It is unlikely that all the abnormalities seen in our study were a result of premature coronary 
artery disease ${ }^{14}$ in view of the youth of our patients (mean age 25 years), lack of symptoms, and different patterns of abnormal systolic or diastolic time intervals. Clearly a spectrum of abnormalities is possible ${ }^{15}$ and our results may reflect an interaction between diabetic small-vessel cardiomyopathy, premature onset of coronary artery disease, and diabetic neuropathy. ${ }^{16}$ Further studies are needed in order to be able to interpret the significance of the various findings in the diabetic patients.

We are indebted to Professor Barbara KrupaWojciechowska for her criticism and suggestions.

\section{References}

1 Ledet T, Neubauer B, Christensen NJ, Lundbaek K. Diabetic cardiopathy. Diabetologia 1979; 16: 207-9.

2 Zoneraich S, Zoneraich O, Rhee JJ, Liao C, Patel MM. Electrocardiographic findings in diabetic patients without clinical evidence of heart involvement. NY State $\mathcal{F}$ Med 1977; 77 : 1254-8.

3 Lewis RP, Rittgers SE, Forester WF, Boudoulas H. A critical review of the systolic time intervals. Circulation 1977; 56: 146-58.

4 Manolas J, Rutishauser W. Relation between apex cardiographic and internal indices of left ventricular relaxation in man. Br Heart $\mathcal{F}$ 1977; 39: 1324-32.

5 Weissler AM, Harris WS, Schoenfeld CD. Bedside technics for the evaluation of ventricular function in man. Am f Cardiol 1969; 23: 577-83.

6 Ahmed SS, Jaferi GA, Narang RM, Regan TJ. Preclinical abnormality of left ventricular function in diabetes mellitus. Am Heart $\mathcal{F}$ 1975; 89: 153-8.

7 Rubler S, Sajadi RM, Araoye MA, Holford FD. Non- invasive estimation of myocardial performance in patients with diabetes. Diabetes 1978; 27 : 127-34.

8 Ahmed SS, Levinson GE, Schwartz CJ, Ettinger PO. Systolic time intervals as measures of the contractile state of the left ventricular myocardium in man. Circulation 1972; 46: 559-71.

9 Voigt GC, Friesinger GC. The use of apexcardiography in the assessment of left ventricular diastolic pressure. Circulation 1970; 41: 1015-24.

10 Gibson TC, Madry R, Grossman W, McLaurin LP, Craig $\mathrm{E}$. The A-wave of the apexcardiogram and left ventricular diastolic stiffness. Circulation 1974; 49: 441-6.

11 Wikstrand J. Non-invasive assessment of cardiac function. Goteborg: GOTAB, Kunngalv, 1976: 167-8.

12 Sanderson JE, Brown DJ, Rivellese A, Kohner E. Diabetic cardiomyopathy? An echocardiographic study of young diabetics. $\mathrm{Br} \mathrm{Med} \mathcal{F} 1978 ;$ i: 404-7.

13 Zoneraich S, Zoneraich O, Rhee JJ. Left ventricular performance in diabetic patients without clinical heart disease. Evaluation by systolic time intervals and echocardiography. Chest 1977; 72: 748-51.

14 Jarrett J. Diabetes and the heart: coronary heart disease. Clin Endocrinol Metab 1977; 6: 389-402.

15 Regan TJ, Lyons MM, Ahmed SS, et al. Evidence for cardiomyopathy in familial diabetes mellitus. $\mathcal{f}$ Clin Invest 1977; 60: 885-99.

16 Gundersen HJG, Neubauer B. A long-term diabetic autonomic nervous abnormality. Diabetologia 1977; 13: $137-40$.

Requests for reprints to Dr Andrzej Rynkiewicz, II Klinika Chorób Wewnętrznych, Akademia Medyczna, Gdańsk ul. Dębinki 7, Poland 80-211. 